\title{
RETHINKING OFFICE AUTOMATION
}

\author{
Margrethe H. 01son
}

and

Jon A. Turner

September 1985

\author{
Center for Research on Information Systems \\ Computer Applications and Information Systems Area \\ Graduate School of Business Administration \\ New York University
}

\section{Working Paper Series}

\section{CRIS 非104}

GBA 非85-74

Presented at the Sixth International Conference on Information Systems, Indianapolis, Indiana, December, 1985.

To appear in Database, July, 1986. 


\section{ABSTRACT}

The debate regarding the impact of technology on work organization and the quality of work life is gaining momentum as a result of office automation and its influence on large numbers of "office" jobs. This paper argues that current approaches to implementation of office automation technology are based on faulty assumptions about both technology and work organization. The result has been systems which fail to live up to the claims of dramatic increases in productivity that typically accompany their implementation. The paper compares information technology to production technology and reviews relevant research on impacts of technology on work organization and management control. An approach to the implementation of office automation systems is proposed, which is based on a new concept of "offices" and "office work". In essence, technology is the facilitator of a wider range of choices in organization and control of office work than was previously possible. When these new choices are considered, the technology can be applied to both improve organizational productivity and effectiveness and to accommodate employees' needs for flexibility and a high quality work life. 


\section{Introduction}

The debate regarding the impact of technology on work organization and the quality of work life seems to go in and out of fashion on a regular basis. Last year, a definitive review of research on the impact of information technology on organizations [Attewell 84] clearly demonstrated that there is no single dimension of organizational impact or single direction of effect on any dimension. The impact of technology on organizations is a result of a complex set of interrelated choices, driven not only by technological availability, but by managerial assumptions regarding technology, work, and workers.

With office automation influencing large numbers of "office" jobs, the debate regarding technology and work is gaining momentum. The debate is particularly important as evidence begins to contradict the claims for improvement in professional and managerial productivity [Turner 85]. It appears that office work is changing, but not in the ways that were predicted. More important, it is now clear that simplistic notions of improving productivity by substituting machines for human labor in the office are hopelessly inadequate. In this paper we examine the impact of office information technology on productivity and work organization of offices. Our basic premise is the following: technology can be used to improve the way offices operate, but accomplishing this requires rethinking our concept of offices and how they function. 
Three basic issues will be addressed:

* The traditional view of technology and work is limited in scope; it assumes a simple division of labor between person and machine. For information technology the choices in division of labor, and the assumptions underlying those choices, are more varied than permitted by previous technologies. Furthermore, choices in the use of information technology for the purposes of control are more varied.

* The traditional conceptualization of offices and office work is rigidly defined. Generally, it consists of a strict hierarchical structure of predefined roles, where the clerical worker is a production system, the professional is a "staff support" or information specialist, and the manager is a decision maker. Furthermore, all this work takes place within fixed well-defined boundaries in space and time.

* The potential impact of information technology is broad, having both direct and indirect components. It encompasses individual quality of work life, horizontal and vertical division of labor, organizational structure and responsiveness to change, and interorganizational interdependence. The impacts, moreover, are evolutionary, representing a cumulative shift in organizational culture rather than discrete changes.

This paper discusses these issues, presents available evidence from recent research, and makes some cautious predictions about the future of office work. First, the technological trends and underlying economic and social trends that influence these changes will be discussed. 


\section{Current Approaches to of $\mathrm{f}$ ice Systems Implementation}

When information technology is introduced into offices in the form of "office automation", the stated objective is generally to improve productivity [Uhlig 79]. The implicit strategy is to replace tasks people perform and equipment they use with procedures executed on a computer (with appropriate peripheral equipment). The expected result of these efforts is that the same amount of office work can be performed by fewer people or that the same number of people can handle a greater volume of work [0lson 82 ].

Closely related to this strategy is one based on the observation that office workers are under-capitalized when compared with other labor categories. For example, office workers are said to have an average capitalization of about $\$ 2000$ /worker for plant and equipment (i.e., a typewriter) while factory workers are said to have $\$ 25,000 /$ worker and agricultural workers have average investments of $\$ 50,000 /$ worker. Presumably, if the investment in equipment were increased for office workers, so would productivity.

Another line of reasoning used to justify office automation follows from Mintzberg's study of managerial work [Mintzberg 73]. He found that managers spent most of their time in meetings or on the telephone rather than preparing documents or thinking. A recent study of "knowledge workers" in multiple organizations demonstrated that half of their time was spent on activities not directly related to their functions and $25 \%$ on "unproductive" activities. These results were attributed to inadequate clerical support and insufficient information [Poppel 82]. Investing in 
office automation would, presumably, remove these constraints on available information and support, permitting the executive to spend more time productively, e.g., in intellectual pursuits or with clients.

While these arguments for investing heavily in office automation have a certain plausibility, we do not see them as compelling. Most office automation efforts have failed to produce the improvements in productivity that were predicted. Few appear able to justify the substantial equipment investment and support expense which the operating unit must pay on a full cost recovery basis.

What accounts for the significant short-fall between anticipated and realized benefits? We believe that the wrong approach to office automation has been taken. First, many applications to date attempt to replicate existing work methods and procedures using the new technology. For example, when word processing is introduced, it is frequently treated as a new form of typewriter. The secretary uses the word processor to type a principal's draft, which is then returned to the principal for proof reading. The marked-up copy is then given to the secretary for entry. This process continues until the principal is satisfied with the product, when the secretary produces an error free copy on the word processing printer and sends copies (often in the company mail) to the addressees.

While simplified error and spelling correction features do reduce somewhat the secretary's effort to produce the memo, the changes are at the margin; they do not produce the magnitude of 
productivity increase suggested by office automation advertisements or warranted by the cost of equipment.

Second, most current approaches to the design of office systems derive the content of work from the characteristics of the technology [Turner 84a]. The worker's job is determined by extending principles used to design the machine portion of the system; the worker is perceived as just one more component of a larger machine. Efficiency of the total system becomes the criterion and any adaptation required is performed by the worker.

Variants on this theme are faddism and positioning. Faddism results when system implementors jump on a popular bandwagon, for example, personal computers or end-user computing, without fully understanding what these concepts mean or their implications. Fashionable themes are co-opted and applied to a project whether or not they make sense. Workers find themselves having to use the fad for no particular reason. Positioning results when implementors spend more time engaged in political activities than in designing a system. Design decisions are made based upon their attractiveness to key actors rather than their appropriateness to the situation. Workers are compelled to attempt to make a coherent job out of the fragments left by system designers.

\section{Underlying Economic and Social Trends}

Despite the problems with current approaches to office systems implementation, the need for office systems is justified by very real economic and social factors. Organizations are faced with difficult choices as a result of significant changes 
in the available work force and costs of accommodating that work force. These changes create problems for which substitution of technology for human resources appears to be a logical solution. These problems are discussed in this section.

Changing Composition of Work

The United States is currently undergoing a painful transition from blue-collar to white-collar work, from an emphasis on products to the provision of services. Office work is no longer a satellite support function to the main business of the firm; in many organizations, even in manufacturing, information processing is a major portion of the basic product, even an end in itself. In the last decade, the number of employed persons performing "office" work has doubled, rising from 20 percent to 40 percent of the total U.S. work force. Changing Demographics of the Work Force

Long-term planning of human resource availability is becoming critical because of significant and rapid changes in the demographics of the work force. Over the next decade the number of new entrants into the work force will decrease dramatically. After women entered the labor force for the first time in large numbers in the last decade, the number of new entrants has leveled off.

Moreover, the fact that women are in the permanent work force to stay introduces a new set of problems for employee and employer. By 1982 in the U.S. 50 percent of women with preschool age children were permanently employed, an increase from 19 percent in 1960. Day care in the U.S. is also inadequate; 
there are two children requiring it for every available slot, and decent quality day care is prohibitively expensive. Furthermore, dual-job and single-parent families need flexibility in their work lives in order to accommodate significant nonwork responsibilities. Few companies have reacted to their employees' needs for flexibility by either providing on-site day care, contributing to community arrangements, or granting employees scheduling flexibility beyond relatively rigid "flex-time" schedules.

Organizational Costs

In every aspect, the costs of housing employees to perform office work are rising. Particularly in urban areas, the costs of housing an office worker are climbing dramatically. In Manhattan, the heart of New York City's office area, a space of 250 square feet per office worker, which cost $\$ 2500$ in 1974 , costs $\$ 10000$ in 1982 , a four-fold increase. Over the same period, salaries of clerical personnel have doubled.

The areas with the greatest potential job growth are those created or altered by the new technology; a consistent shortage of personnel with critical technical skills (e.g. word processing, programming) requires management to search for more "creative" ways to attract and/or retain qualified people with these skills. One in six jobs goes unfilled in computer-related technical positions. 


\section{Developments in Information Technology}

The purpose of this section is to provide a few observations about the phases of technological assimilation in office automation [McFarlan 83] typical of most large organizations rather than to provide a complete review of developments in information technology. Two trends predominate:

* Special-purpose to general-purpose systems.

* Stand-alone to networked systems.

Special-Purpose to General-Purpose

This trend is best exemplified by the shift from specialized word processors to personal computers with word processing capabilities (provided by a program). One researcher has observed that word processing as a separate organizational function had become obsolete by 1984 [Johnson 84]. This development parallels an earlier trend from centralized information systems, which required specialized staff support, to dispersed, online, interactive systems with distributed support.

With word processing, as with specialized input functions (i.e., data entry), specific technical skills are required to "operate the machine". When generalized hardware and software are used, knowledge about the "operation" of the machine is a "universal" skill which is acquired by a greater number of people in the work unit. (We do not preclude a trend back toward special-purpose machines in the future; indeed we think that likely. However, specialized modular components will be available to many workers and "operating the machine" will continue to be a generalized skill which many employees acquire). 
Stand-alone to Networked

A stand-alone system refers to one which is operated by one person at a time, and for which there is no capacity to "pass" information back and forth with other systems except through human intervention (i.e., reenter data or transmit it via a diskette). The important aspect of this difference is that a stand-alone system emphasizes or encourages individual flexibility and control, while a networked system emphasizes organizational flexibility and control. In a typical large organization today, personal computers are operated on an individual (stand-alone) basis; resources are being expended to "network" them as quickly as possible in order to regain organizational control over information and increase overall organizational flexibility.

General Organizational Trends with Technology

While we do not want to over-generalize, we think it is fair to say that most large organizations which have made a commitment to office automation:

* have moved from special-purpose to general-purpose system support;

* are rapidly moving from stand-alone to networked system support.

For our purposes, one final point about technological trends must be made. Assuming an organization has reached the stage where general-purpose, networked, information system resources are readily available, there are a wide range of choices regarding the organization of human resources around those system 
resources. In particular, there are many options with respect to:

* Work organization, both in terms of the work an individual performs and the distribution of work among individuals and work groups.

* Control over the work, both in terms of method (monitoring, pacing, counting, etc.) and availability of control information (to supervisors, workers, management).

Current approaches to office systems implementation, in which technology is treated as a constant, tend not to take advantage of the variety of options in terms of work organization and control. Rather, a new concept of offices and office work is required, in which the economic and social factors discussed above provide the motivation to reconceptualize office work; information technology is the facilitator of the new office concept.

\section{Experience To Date Regarding Technology and Work Organization}

What is known about the relationship between information technology, work organization, and management control? To begin to answer this question, two other questions must be addressed:

* What is the relationship between production technology, work organization, and management control?

* What are the similarities and differences between production technology and information technology?

These questions are highly complex and cannot be answered 
completely within the scope of this paper. However, the major themes underlying them will be highlighted.

Production Technology and Work Organization

The term "technology", in the context of organization theory, has been used to refer to a variety of aspects of work. Hunt [Hunt 72] offers a useful definition as a starting point. He refers to the technical system as the "collective instruments used by operators to do their work" [Mintzberg 79]. According to this definition, three dimensions of technology encompass its variations: flexibility (or location of control over work), complexity (or sophistication of the instruments used), and knowledge required (of workers) to operate the instruments. In the next section we will present a framework of work organization which basically encompasses the same dimensions. We therefore posit that in the sense of organization theory, technology and work organization are interdependent concepts. In general, the term "technology" has been used to refer to augmentation of physical tasks; with information technology and the augmentation of cognitive tasks, the interdependence becomes even more evident (as will be discussed in the next section).

A number of important research studies have documented the relationship between technology and organization structure [Woodward 65, Thompson 67, Perrow 79, Pugh 68]. It is not possible within the scope of this paper to review these studies (the reader is referred to [Hall 83] for an excellent review). They generally assume a single dominant "technology" for the organization as a whole, which is consonant with the overall structure. 
In general, these "macro-level" studies of technology have supported what has been referred to as the "curvilinear hypothesis" [Shepard 77]. In Woodward's seminal study, for example [Woodward 65], she demonstrated that "craft" organizations were very "organic" and unformalized while organizations with large batch or assembly systems were highly "bureaucratic", standardized and formalized. Organizations with a high level of automation (process control), tended to be "organic" and less formalized, completing the "U" shaped diagram. Woodward and other "technological theorists" did not hypothesize that organizations went through stages of automation from highly labor-intensive (i.e. craft) to assembly to automated; it was the nature of the output produced which dictated the appropriate technology. It is in this aspect of "technology" that there may be the most critical difference today: both in production technology and information technology, organizations have choices about the type of work process to utilize, or the relative balance between person and machine in that work process. Thus the research on production technology of the last two decades is highly relevant today, but further research is required which takes into account this broader set of organizational choices.

Another relevant body of research concerns the individual level of work organization and the division of labor, both among workers and between worker and machine. Most of this work, with a few exceptions [Faunce 65, Shepard 71], has focused primarily on production work as well. One stream of research supports a basic contention laid out by Braverman [Braverman 74]: there is a pervasive tendency for jobs in capitalist organizations to be reorganized at lower skill levels than previously [Attewell 82]. 
Evidence in support of this thesis abounds, primarily in the form of case studies which focus on office work [Glenn 79] as well as production work [Noble 79].

The "curvilinear hypothesis" [Shepard 77], already noted, provides a counter-argument to Braverman's thesis at the level of individual work organization. According to this thesis, technology as applied to the work does progressively reduce the skill level required of the worker, but only up to a point. The next phase is automation of the simplest and most repetitious parts of the work. The work that remains is upgraded in skill requirements, involving more machine maintenance and monitoring than physical effort. This thesis has been demonstrated with production work in certain technologically advanced industries [Blauner 64, Faunce 65, Shepard 71, Attewell 82]; it is now being demonstrated with automated assembly-line manufacturing via robotics.

Information Technology and Work Organization

The general definition of technology given above is directly applicable to information technology in industries where the primary workflow consists of information rather than physical materials. An excellent review of the impacts of information technology on organizations at both the macro (organization structure) and micro (individual work) levels is contained in [Attewell 84]. Only selected research focusing on individual work will be highlighted here.

The first debates regarding office automation and deskilling appeared in the early 1960's; the bulk of research to date is 
from that decade. Braverman [Braverman 74] demonstrates his thesis of progressive deskilling in the evolution of clerical office work. A review by Shepard [Shepard 71] lists seven studies which show that rather than systematic deskilling, lowerlevel clerical positions were eliminated due to automation and the proportion of higher-level clerical jobs increased. A more recent study of the insurance industry shows the same trend [Attewell 83]. In an interesting case study of a bank, Adler [Adler 82] shows how the evolution of the bank teller's job supports the curvilinear hypothesis. He identifies four phases of change in the job as a result of computer support. While the first three phases represent progressive deskilling, the fourth phase ("integrated computer processing") represents a significant upgrading of skills. In this phase "the role of the worker is to assure the interface between the computer and the client", and the job requires both job-specific skills (including operation of a computer) and general knowledge of "the banking business" [Adler 82].

Further evidence of the upgrading of skills required in information-intensive industries such as banking is provided by the movement of back office operations out of urban areas. In New York City, for example, the ability to gain access to an educated female suburban work force has been an important factor in the relocation of "back-office" operations out of the central city. This movement has accelerated over the last decade as increasing reliance on electronic systems has upgraded the skills required [Moss 83 ]; at the same time, physical constraints on the location of the work have been removed. 
Surveys of Word Processing

In the U.S., a great deal of attention has been paid to the potential for word processing to create massive deskilling of clerical jobs. Although there are isolated incidents of the technology being introduced in this way, evidence from recent surveys shows that employees feel otherwise [Honeywell 83 ; Professional83; Kelly83;9to584]. When employees were asked about the effect of word processing on their work, the overwhelming majority felt the new skill had a positive effect. In one survey [Kelly 83], ninety percent of the respondents felt that word processing had improved their chances for advancement. In another [9 to 584 ], 70 percent felt their jobs were more interesting and more enjoyable; only 6.5 percent reported their jobs were more routine.

Another potential problem is indicated, however, by the three surveys of office workers where managers were also interviewed [Professional 83;Kelly83;Honeywel183]. Their perceptions differed sharply from those of the employees on two important points: they did not feel the employees' skills had been upgraded, nor did they feel the employees' chances for advancement had increased. Thus, this relatively "mature" office technology is beginning to show a generational effect: an increase in employee frustration and alienation is likely when potential rewards and advancement based on upgraded skills do not materialize. Nevertheless, there is little evidence of the perception of deskilling.

The results of the word processing surveys demonstrate that to view job changes in terms of "upgrading" and "downgrading" of 
skill levels is problematic. In the next section we will present a framework which takes into account multiple dimensions of work organization.

\section{Toward a New Concept of of $f$ ice Work}

office automation can provide significant organizational opportunities for improved performance and effectiveness if it is utilized as an opportunity to re-design the content of jobs. That is, new information technology permits relaxing constraints on what tasks workers perform, the location where they are performed, and the control systems to ensure their performance. Consequently new work arrangements can be created that greatly reduce cost, improve the quality and timeliness of a product, and increase organizational flexibility.

Consider the following example. The foreign division of one, large, commercial bank put loan proposals together by drawing the agreement in the field, TELEXing it back to the home office for modification, TELExing it back to the field for approval, and so on. Intermediaries, called Customer Service Officers (CSO), handled much of the communication from the field, acting on behalf of the field officer to obtain support of the various operating departments. Loans took as long as 15 days to initiate and sales were being lost to competitors who could close a deal more quickly. An integrated office system with electronic mail, word processing, filing, and access to the bank's application systems permitted loan initiation to be reduced to three days. Moreover, csos became less involved. People in the field used the system to communicate directly with the operations department, reducing the number of intermediate steps and 
documents produced in order to execute a transaction. It was the reallocation of tasks among workers that resulted in productivity and quality improvements, rather than the technology itself. Had the same tasks as before been performed with the new technology, the improvements would probably have been much less substantial.

Office Systems Goals

The approach starts with a business goal; for example, putting together creative loan packages in the field for potential clients. Then, one considers what is necessary to accomplish this goal. In this case, information about the potential client's financial condition, past performance in meeting credit obligations, economic and industry forecasts, and the institution's current commitment to loans of this type are needed to assess benefits and risks. In order to configure a specific package, boiler-plates for similar loans and the appropriate paragraphs describing the particular arrangement must be included. The draft must be reviewed by the legal department (to insure that it conforms to the institution's procedures) and by senior management.

After the basic business goals have been established, the focus quickly shifts to the organizational tasks required and the effectiveness of various alternative configurations of these tasks. This is a "systems" approach which is not driven by technology; office automation simply assures new and potentially highly effective alternatives. In the example, focus shifts to the field representative; what will the content of this new job be, what skills will be required to perform it and how will performance in this position be determined? Given this new job, 
how should the content of other jobs be shifted, particularly in those jobs providing direct support? What form of interdependence should exist among the new set of jobs? Only after this point does one begin to consider the form of a technical system to deliver this information and provide the needed connectivity.

In summary, we see the implementation of information technology being driven by a business goal, closely aligned to corporate strategy and the restructured content and configuration of work, rather than being driven by the characteristics of the technology. This shifts the emphasis of implementation away from the parameters of equipment and the features of software to the information needed as well as the motivation, skills, control, and incentives of the people utilizing that information in their work .

If the potential opportunities inherent in information technology are to be realized, new concepts and a new vocabulary of design will be needed.

Office Systems Design Concepts

Six aspects of work organization underlie the new vocabulary of design. The actual terms have been used somewhat differently in other contexts; however, the important issue is that the critical aspects of work organization are covered with the vocabulary we have chosen.

* Division of labor

* Work flow

* Skill level

* Control

* Interdependence among workers 
* Work unit configuration

Division of labor refers to the allocation of tasks between a person and a computer. Alternatives range from having a person perform as many tasks as possible to having a computer perform all of the tasks it can be programmed to perform. The interesting alternatives lie in between these extremes, where certain tasks are allocated to the person and others to the computer.

There are various strategies for allocating tasks between a person and a computer including:

1. Allocate all jobs to the computer that can be performed by a computer. The human may experience wide fluctuations in work load with extensive periods of inactivity.

2. Allocate those tasks to a human that result in the most efficient computer processing. This approach maximizes machine utilization and performance. The worker may not have a coherent job and overall performance may be sub-optimal.

3. Match between the information processing demands of a task and the characteristics of human and computer. For example, humans are good at cognitive tasks, such as determining goals and formulating generalizations while computers are efficient at calculation and data transmission.

4. Use the human as a supervisory controller. This involves monitoring for events that require human intervention, executing the intervention, taking manual control of the process, planning (including reprogramming of the computer) and training. The computer performs all other tasks. 
5. Allocate tasks dynamically to whichever processor, human or computer, has the greatest instantaneous capacity for performing the task. This approach results in minimizing fluctuations in work load for the human.

A more complete discussion of these alternatives can be found in Turner and Karasek [Turner $84 \mathrm{~b}$ ].

Work flow refers to the way a processing system is organized. The approach common with non-automated jobs is that work is organized as a complete process, where all of the processing takes place on a particular unit or transaction before the next item is handled. In production technology this is analogous to a job shop, or to use Woodward's terminology [Woodward 65], a craft shop. Each job entails multiple tasks which require a significant amount of knowledge (see skill level below).

Alternatively, work may be organized as an assembly-linel, where all of the processing of a particular type is performed before the next step is commenced. This approach suggests a high degree of task specialization (see skill level below).

Assembly-line systems, in Woodward's terminology [Woodward 65] large batch or mass production, are relatively easy to design and control because the work steps can be separated, reducing complexity and interactions among components. These systems tend to be efficient because the handling of all items in the same step minimizes overhead. They are, however, inflexible.

\footnotetext{
${ }^{1}$ In industrial engineering terms, a continuous process.
} 
Complete processing of an item must wait for all its cohorts and the content of human jobs is pretty much dictated to be a "narrow" slice of the total scope of work. This form of work organization tends to make poor use of human skills and offers few opportunities for the construction of meaningful jobs. It also requires product uniformity and thus sacrifices uniqueness, one of the keys to providing successful services.

Information technology permits a third form of work organization, complete automation, where the operator becomes a controller or monitor (see previous section on division of labor). In production technology, this form of work flow is becoming a replacement for assembly lines as a result of robotics technology. In this type of work flow, the operator's job is changed from one of doing to one of supervising. Some research has shown that the nature of this work requires the operator to have an expanded set of skills [Woodward 65, Attewell 84].

Past research on organization of work assumed that the nature of the product determined the work flow of the production system and, largely, the content of the worker's job. With information technology, many forms of work flow are permissible and the system designer is no longer limited by the form of the product or the technology.

As Drucker [Drucker 85] observes, information technology often permits collapsing structure by the removal of intermediate levels of management whose primary function was reporting status and the coordination of activities. These "flatter" structures rely more on self motivation and control of individual workers 
than the authority mechanisms of hierarchical organizations.

Skill level refers to the knowledge required by a worker in order to accomplish a job. It is composed of two components: the number of different tasks a worker performs and the knowledge or training required to perform each task. At one extreme, involving low skill levels, the work is subdivided into the smallest and most simple units with a different person performing each unit repetitively. The goals are to improve the efficiency of the entire process and to reduce the skill level of any individual employee, thus making workers more easily replaceable. At the other extreme, involving high levels of skill, a single person performs many related tasks, in an integrated fashion, each one requiring considerable expertise ${ }^{2}$.

From the studies on word processing cited earlier (and other research), it is evident that workers desire and are motivated by the opportunity to acquire and use new skills. A major issue for management then becomes how to provide the mechanism for people to acquire and retain these skills. Again, prior research suggests that as long as middle management perceives that workers have not developed new skills through their use of information technology, a serious conflict exists. Rather than leading to improved worker performance, these false expectations, if they persist, may well lead to frustration and antagonism.

2 Jobs with a relatively high degree of knowledge are often referred to as enriched jobs. For work which is primarily nonsupervisory, enriched jobs tend to have greater motivational appeal, resulting in higher productivity and satisfaction, than jobs that are not enriched. 
Control is a multifaceted notion relating to 1) the extent to which a person can select work processes used in a job, 2) the degree of separation between planning of the work effort and its execution, and 3 ) the extent to which others are aware of the status of the work. With external control, a worker has few prerogatives with respect the selection of work methods or pacing, the mental activities of goal identification and action planning are separated from the execution of tasks, and the work situation is completely visible to management. Under these conditions, due to a constrained scope, it is difficult for a worker to correct errors and invoke new strategies for goal accomplishment.

With internal control, workers can select the method best suited to accomplishing a task, and the planning of what to do is integrated with its execution. A worker can then monitor the job, detect errors, and apply corrections; thus the quality of the product or service is improved, and the worker benefits from direct feedback on performance. Not only is this more efficient, but the worker also becomes closely associated with the end product.

Some researchers prefer to treat skill level and control together under the concept of specialization [Mintzberg 79]. We believe they represent different and significant aspects of work organization, and consequently, must be treated separately by office system designers.

Interdependence is the extent to which a worker is dependent upon others in performing a job. Thompson's [Thompson 67] 
notions of pooled, sequential and reciprocal interdependence provide a useful framework for describing implications for office work. With pooled interdependence, one worker may be dependent upon a resource pool; for example, a group of analysts sharing a personal computer. With sequential interdependence, the tasks of one worker must be completed before those of another can be started; for example, a copy editor completing work before typesetting is begun. The third type, reciprocal interdependence, exists when workers must continuously interact in order to produce a product.

It is easiest to design an office system for pooled interdependence situations, particularly if the resource in question is a data base or some other information resource. Sequential interdependence can also be accommodated if the form of intermediate product is well defined, although inefficiencies do result when workers must wait for products. Reciprocal interdependent situations are the most difficult to support with office systems due to the complex nature of interactions among actors and usually, a lack of knowledge as to precisely which factors influence outcomes. Research on task argumentation, tools for the support of group processes when a work group is not co-located (see next section), and cooperative distributed problem solving ${ }^{3}$ may provide insights into the design guidelines for office systems support for reciprocal interdependence.

$3_{A}$ distributed network of semi-autonomous processing nodes that work together to solve a single problem. Each node is an independent problem solving system that can modify its behavior as circumstances change and plan its communication and problem solving strategies with other nodes. 
Work unit configuration refers to where and when work is performed. One dimension, "spatial dispersion" [Brandt 83], refers the geographical location of a work unit. A second dimension, "time dispersion", indicates when work of a unit is performed. At one extreme, high configuration, the members of the work unit are co-located on the employer's premises, all working at the same time (a traditional office). At the other extreme, low configuration, the members of the work unit are dispersed, all working remotely from the office (e.g., at home) and each other and not necessarily at the same time.

Office systems technology permits the relaxing of constraints so that offices can shift from high configuration to low configuration structures. Shifts have already occurred on a functional basis in information-intensive industries such as insurance and banking; the location of a function is determined by costs of space and energy and availability of a qualified labor pool, while telecommunications and computing technology facilitate a broader range of choices. As another example, multi-national organizations utilize telecommunications to efficiently coordinate geographically dispersed tasks operating in different time zones.

We believe that low configuration office structures will become more common and will require methods of coordination, control, and supervision that are significantly different from those appropriate to a traditional office. In particular, work groups will be non-co-located and individuals will be supervised remotely. Furthermore, some jobs will be shifted out of the hierarchical control structure and be contracted out to 
individuals acting independently. As Brandt [Brandt 83] observes, when a person becomes an independent contractor instead of being a member of a large organization, coordination is accomplished by the market for services rather than by the authority structure of the company.

\section{Putting Things Together}

The transition to a service economy is creating a demand for skilled office workers that will not be met by new entrants into the labor market. This trend, coupled with increasing office and transportation costs, will encourage organizations to explore alternative arrangements that open new pools of qualified workers or facilitate retraining components of the existing work force.

In contrast to previous technologies that were limited by their lack of generality and their isolated nature ${ }^{4}$, information technology has permitted the design of work processes to be relatively independent of either the product or the technology used to produce the product. Consequently, technology, which used to be a constraint, is now an opportunity. Emphasis needs to shift to policies, their selection, and the values and goals of stake-holders. Business goals and job design, rather than technology, can and should drive office systems implementations.

The division of labor between human and machine is no longer dictated by economies of scale of operations, or of the equipment. Division of labor between workers and machines that

4 That is, the inability to be interconnected with other similar systems and to exchange useful information. 
takes advantage of the strengths of each, and focuses on machine compensation for short term variations in operator capabilities rather than the reverse, should lead to higher performance of the total system.

The limitations of work flow based on assembly lines well expressed by an executive in a large financial institution:

The assembly-line channel, in which each worker was responsible for just a single function or piece of the total flow, was obsolete in an organization geared to markets, customers, and custom-tailored services. [Matteis 79, p. 154]

People require a broad perspective and flexibility of action if they are to exhibit goal-directed behavior now desired by management. Systems that support complete processes permit that broad perspective and flexibility.

Emphasizing internal control requires management to reconsider its perception of workers - treating them more as partners than as adversaries. The motivational benefits of this strategy outweigh the difficulty of changing opinions of managers about workers. Some recent labor-management agreements suggest a general realignment of perceptions and prerogatives may not be unthinkable.

Jobs with pooled and sequential interdependence have been the primary target for information technology to date. Improving the performance of professional and managerial jobs requires attention to systems which support reciprocal interdependence. To date, the concept of a "workstation" has really been based on the tools and functionality required of an individual working 
alone. Research on the technological tools to support work groups (ad hoc as well as permanent, highly structured as well as unstructured, in face-to-face meetings as well as non-co-located, in decision making as well as task performance) is needed and is now beginning to emerge.

Furthermore, creative executives will find ways to move jobs from high to low configuration, taking advantage of new ways of structuring work. Flexibility in location, timing, and coordination of tasks and the individuals performing them is a significant aspect of overall organizational flexibility, a critical component successful organizational performance.

\section{Conclusion}

Information technology to support a new concept of office work is feasible today, although not in common use. We feel that the significant drawback to utilizing the technology in ways that improve both organizational effectiveness and employee (work and nonwork) needs will not be the technology, but organizational culture. By this term we refer to traditional views of work, in which an employee's skills and abilities are downgraded in value and external control is deemed necessary, and of technology, in which tools are applied to replicate the same tasks and the worker is viewed as a simple component of a larger machine.

The design principles we have sketched out can be used creatively where traditional assumptions of work and technology have been replaced by an "enlightened" set of assumptions: workers have skills and abilities which can and should be used to their fullest extent, internal control is an effective mechanism 
for improving motivation and productivity, a system in which the worker controls the technology rather than vice versa is technically feasible and cost-effective.

Information technology will not cause changes in managerial assumptions about workers and technology; however, it does negate some of the major underlying premises of those assumptions. Furthermore, it facilitates a greater number of alternatives that accommodate enriched jobs, greater internal control, and employee needs for flexibility. It is the responsibility of both system implementors and managers to ensure that the tremendous power and flexibility of information technology be applied in ways that improve quality of work life as well as organizational effectiveness. 


\section{References}

[9 to 584 ] 9 to 5 National Association of Working Women. National survey on women and stress. 9 to 5 National Association of Working Women, 1984 .

[Adler 82] P. Adler. Rethinking the skill requirements of new technologies. Technical Report 84-27, Harvard Business School, Boston, MA, 1982. Working Paper.

[Attewell 82] P. Attewell. The de-skilling controversy. Research Report, Department of Sociology, State University of New York at Stony Brook, Stony Brook, 1982.

[Attewell 83] P. Attewell. Microelectronics and employment. Technical Report, University of California at Santa Cruz, Santa Cruz, CA, 1983. Conference on Microelectronics in Transition.

[Attewell 84] P. Attewell and J. Rule. Computing and organizations: What we know and what we don't know. Comm. of the ACM 27(12):1184-1192, 1984 .

[Blauner 64] R. Blauner. Alienation and Freedom: The Factory Worker and His Industry. University of Chicago Press, Chicago, IL, 1964 .

[Brandt 83] S. Brandt. Working-at-home: How to cope with the spatial design possibilities caused by the new communication media. Office: Technology and People 2(1):1-14, 1983.

[Braverman 74] H. Braverman. Labor and Monopoly Capital: The Degradation of Work in the Twentieth Century. Monthly Review, New York, 1974 .

[Drucker 85] P. Drucker. Playing in the information-based orchestra. Wall Street Journal June 4, 1985.

[Faunce 65] W. A. Faunce. Automation and the division of labor. Social Problems 13(Fall):149-160, 1965.

[Glenn 79] E. Glenn. Proletarianization of clerical work:

Technology and organizational control in the office. Case

studies on the Labor Process. Monthly Review, 1979.

[Hall 83] R. H. Hall. Organizations: Structure and Process. Prentice Hall, Englewood Cliffs, NJ, 1983. 3rd. Edition. 
[Honeywell 83] Honeywell, Inc. Office automation and the workplace: A national survey. Technical Report, Honeywell, Inc, Minneapolis, MN, 1983.

[Hunt 72] J. W. Hunt. The Restless Organization. Wiley International, 1972, Chapter 6.

[Johnson 84] B. Johnson. For those who do not like to make coffee. 1984.Presentation to the National Symposium on Women, Technology and office Work, National Academy of Sciences.

[Kelly 83] Kelly Services, Inc. The Kelly report on people in the electronic office. Technical Report, Kelly Services, Inc., Troy, MI., 1983.

[Matteis 79] R. J. Matteis. The new back office focuses on customer service. Harvard Business Review :146-159, Mar.-Apr., 1979.

[McFarlan 83] F. W. McFarlan and J. L. Mckenney. Corporate Information System Management: The Issues Facing Senior Executives. Richard D. Irwin, Homewood, IL, 1983.

[Mintzberg 73] H. Mintzberg. The Nature of Managerial Work. Harper \& Row, New York, NY, 1973.

[Mintzberg 79] H. Mintzberg. The Structuring of Organizations. Prentice-Hall, Englewood Cliffs, NJ, 1979.

[Moss 83] M. L. Moss. Back office operations: Emerging trends and policy options. 1983.Graduate School of Public Administration, New York University, New York, NY.

[Noble 79] D. F. Noble. Social choice in machine design: The case of automatically controlled machine tools. Case Studies on the Labor Process. Monthly Review, 1979.

[Olson 82] M. H. Olson. New information technology and organization culture. MIS Quarterly 6(SI):71-92, 1982.

[Perrow 79] C. Perrow. Organizational Analysis. Wadsworth, Belmont, CA, 1979.

[Poppel 82] H. L. Poppel. Who needs the office of the future? Harvard Business Review :146-155, Nov.-Dec., 1982. 
[Professional 83]

Professional Secretaries International. The evolving role of the secretary in the information age. Technical Report, Professional Secretaries International, 1983.

[Pugh 68] D. S. Pugh, D. J. Hickson, C. R. Hinings and C. Turner. Dimensions of Organizational Structure. ASQ $13(1): 56-105,1968$.

[Shepard 71] J. Shepard. Automation and Alienation: A Study of office and Factory Workers. MIT Press, Cambridge, MA, 1971.

[Shepard 77] J. M. Shepard. Technology, alienation, and job satisfaction. Annual Review of Sociology 3:1-21, 1977.

[Thompson 67] J. D. Thompson. Organizations in Action. McGrawHill, New York, NY, 1967.

[Turner 84a] J. A. Turner. Computer mediated work: The interplay between technology and structured jobs. Comm. of the ACM 27(12):1210-1217, 1984 .

[Turner 84b] J. A. Turner and R. A. Karasek, Jr. Software ergonomics: Effects of computer application design parameters on operator task performance and health. Ergonomics 27(6):663-690, 1984 .

[Turner 85] J. A. Turner. The organization of work with integrated office systems: A case study in commercial banking. Research Report, New York University, Center for Research in Information Systems, 1985.

[Uhlig 79] R. P. Uhlig, D. J. Farber and J. H. Bair. The office of the Future. North-Holland, Amsterdam, 1979.

[Woodward 65] J. Woodward. Industrial Organization: Theory and Practice. Oxford University Press, London, England, 1965. 